\title{
microRNA-630 promotes cell proliferation and inhibits apoptosis in the HCT116 human colorectal cancer cell line
}

\author{
LIJUAN ZHANG ${ }^{1}$, GANG FENG $^{2}$, XINYAN ZHANG ${ }^{3}$, YAWEN DING $^{2}$ and XIAOJUAN WANG ${ }^{2}$ \\ ${ }^{1}$ Department of Oncology, Aerospace Center Hospital, Beijing 100049; ${ }^{2}$ Department of Oncology, Wuhan Puai \\ Hospital, Wuhan 430033; ${ }^{3}$ Department of Gastroenterology, Aerospace Center Hospital, Beijing 100049, P.R. China
}

Received June 2,2016; Accepted April 20, 2017

DOI: $10.3892 / \mathrm{mmr} .2017 .7159$

\begin{abstract}
Dysregulation of microRNAs (miRNAs) in colorectal cancer provides important opportunities for the development of future miRNA-based therapies. The present study aimed to assess the role of miRNA-630 (miR-630) expression in colorectal cancer. HCT116 human colorectal cancer cells were transfected with miR-630 inhibitor, mimic or control miRNA, and the effects of miR-630 dysregulation on cell viability, proliferation and apoptosis were analyzed using MTT and bromodeoxyuridine assays, and an annexin V-fluorescein isothiocyanate cell apoptosis kit, respectively. In addition, the changes in the protein expression of proliferation-associated and AKT signaling pathway proteins were analyzed by western blot analysis. The results of the present study demonstrated that overexpression of miR-630 significantly promoted HCT116 cell proliferation however inhibited apoptosis. Furthermore, miR-630 overexpression reduced the protein expression of p27, BCL2-associated X apoptosis regulator, procaspase- 3 and active caspase-3, and increased the levels of phosphorylated-AKT and BCL2 apoptosis regulator. The suppression of miR-630 led to the opposite results. In conclusion, the present findings suggested that miR-630 may function as an oncogenic miRNA in colorectal cancer, and may promote cellular proliferation and inhibit apoptosis, through the regulation of the expression of $\mathrm{p} 27$ and the AKT signaling pathway. The present study suggested that the inhibition of miR-630 may have potential as an alternative therapeutic strategy for the treatment of patients with colorectal cancer.
\end{abstract}

Correspondence to: Dr Lijuan Zhang, Department of Oncology, Aerospace Center Hospital, 15 Yuquan Road, Beijing 100049, P.R. China

E-mail: zhanglijuan9109@126.com

Key words: microRNA-630, colorectal cancer, cell proliferation, apoptosis

\section{Introduction}

Colorectal cancer is the third most common cancer worldwide with a high rate of morbidity and mortality (1). Each year, there are over one million newly diagnosed cases and approximately 600,000 cases of colorectal cancer-associated mortality (2). The major risk factors of colorectal cancer are increasing age and lifestyle factors, and other risk factors include obesity, insulin resistance and metabolic syndrome (3). The survival of this disease has improved considerably, however, the 5-year relative survival for patients aged 65 years and older remains as low as $60 \%$ (2). An improved understanding of the underlying mechanisms of colorectal cancer may provide valuable information for treating this disease.

microRNAs (miRNAs) are endogenous, evolutionarily conserved, single chain noncoding RNAs consisting of 19-22 nucleotides, which inhibit mRNA transcription or induce mRNA degradation and have been used in cancer research (4-6). Various studies have demonstrated that miRNAs have critical roles in tumor cell proliferation, differentiation, apoptosis, gene regulation and formation by base-pairing with the 3'-untranslated region of target mRNAs $(4,7,8)$. Altered expression of miRNAs contributes to the pathogenesis of the majority of types of human cancer, including colorectal cancer $(9,10)$. To date, a variety of miRNAs, including miR-18a, miR-1, miR-133b and miR-374a, have been reported as regulators in a range of mechanisms in colorectal cancer $(1,11,12)$. Therefore, dysregulation of miRNAs in colorectal cancer provides important opportunities for the development of future miRNA-based therapies (9).

miR-630 is an miRNA that is located at chromosome $15 q 24.1$ (13). Its expression is reduced in various cancer types, including breast cancer and hepatocellular cancer $(13,14)$, while is reported to be increased in colorectal cancer (15). To the best of our knowledge, no previous studies have reported the functional effects of miR-630 on colorectal cancer cells. Therefore, the objective of the present study was to investigate the potential role of miR-630 in colorectal cancer, which could be associated with tumor pathogenesis. The expression of miR-630 in HCT116 human colorectal cancer cells was suppressed or overexpressed by transfection with miR-630 inhibitor or mimic. Subsequently, the cell proliferation, apoptosis and the protein expression of eight associated proteins were investigated in miR-transfected cells in order to 
provide a basis for understanding the function of miR-630 in colorectal cancer.

\section{Materials and methods}

Cell culture and transfection. The HCT116 human colorectal cancer cell line was obtained from the China General Microbiological Culture Collection Center (Institute of Microbiology, Chinese Academy of Sciences, Beijing, China) and maintained in RPMI-1640 medium (Gibco; Thermo Fisher Scientific, Inc., Waltham, MA, USA) supplemented with $10 \%$ fetal bovine serum (Gibco; Thermo Fisher Scientific, Inc.), $100 \mathrm{U} / \mathrm{ml}$ penicillin and $100 \mathrm{U} / \mathrm{ml}$ streptomycin (Gibco; Thermo Fisher Scientific, Inc.) at $37^{\circ} \mathrm{C}$ in a humidified atmosphere of $5 \% \mathrm{CO}_{2}$ (16). For cell transfection, miR-630 inhibitor, mimic and control were synthesized by Guangzhou RiboBio Co., Ltd. (Guangzhou, China). Cells were seeded in antibiotic-free RPMI-1640 medium in 24-well plates at a density of $2 \times 10^{5}$ cells/well. Transfection was performed using Lipofectamine ${ }^{\circledR}$ RNAiMAX reagent (Invitrogen; Thermo Fisher Scientific, Inc.), according to the manufacturer's protocol (17). The sequences of the oligonucleotides that were used were as follows: miR-630 mimic, sense 5'-AGUAUU CUGUACCAGGGAAGGU-3', antisense 5'-CUUCCCUGG UACAGAAUACUUU-3'; miR-630 inhibitor, sense 5'-ACC UUCCCUGGUACAGAAUACU-3'. The control sequence was scrambled, 5'-TTCTCCGAACGTGTCACGTTTC-3'. Cells were transfected for $48 \mathrm{~h}$ at $37^{\circ} \mathrm{C}$ with $50 \mathrm{nM}$ miR- 630 mimic, $200 \mathrm{nM}$ miR-630 inhibitor, and $100 \mathrm{nM}$ control. Following transfection, cells were collected for subsequent analyses.

Cell viability assay. Cell viability was assessed using an MTT assay. Cells were first transfected with miR-630 inhibitor, mimic or control for $48 \mathrm{~h}$, as aforementioned. Cells were subsequently collected and seeded in 96-well plates at a density of $1 \times 10^{4}$ cells/well. Following culture for $1-5$ days at $37^{\circ} \mathrm{C}, 20 \mu \mathrm{l}$ MTT (10 mg/ml; Sigma-Aldrich; Merck KGaA, Darmstadt, Germany) was added to each well and incubated for $4 \mathrm{~h}$ at $37^{\circ} \mathrm{C}$. Subsequently, $150 \mu 1$ dimethylsulfoxide (Beijing Solarbio Science \& Technology Co., Ltd., Beijing, China) was added to each well to dissolve the formazan crystals. The plates were agitated for $10 \mathrm{~min}$ and the absorbance was measured using a microplate reader (Bio-Rad Laboratories, Inc., Hercules, CA, USA) at a wavelength of $570 \mathrm{~nm}(18)$.

Cell proliferation assay. Cell proliferation was measured following transfection with miR-630 inhibitor, mimic or control using a bromodeoxyuridine (BrdU) assay. Briefly, cells were seeded in 6-well plates at a density of $5 \times 10^{4}$ cells/well on sterilized coverslips. Following $72 \mathrm{~h}$ of incubation at $37^{\circ} \mathrm{C}$, $10 \mu \mathrm{M}$ BrdU (Sigma-Aldrich; Merck KGaA) was added to each well and cells were incubated for $1 \mathrm{~h}$ at $37^{\circ} \mathrm{C}$. Cells were fixed in $4 \%$ paraformaldehyde for $15 \mathrm{~min}$ and permeabilized with $0.3 \%$ Triton X-100 for $10 \mathrm{~min}$ at room temperature. Cells were blocked with $10 \%$ normal goat serum (Sigma-Aldrich; Merck $\mathrm{KGaA}$ ) in PBS for $20 \mathrm{~min}$ at room temperature. Subsequently, cells were incubated with a mouse anti-BrdU antibody (cat. no. 560210; 1:20; BD Biosciences, San Jose, CA, USA) for $12 \mathrm{~h}$ at $4^{\circ} \mathrm{C}$ and a secondary antibody coupled to a fluorescent marker (cat. no. A-11032; 1:200; Alexa Fluor ${ }^{\circledR}$ 594; Invitrogen;
Thermo Fisher Scientific, Inc.) for $2 \mathrm{~h}$ at room temperature. Cell nuclei were stained with $1 \mathrm{mg} / \mathrm{ml}$ DAPI (1:1,000; Vector Laboratories, Inc., Burlingame, CA, USA) for $12 \mathrm{~min}$ at room temperature. The stained cells were visualized using a fluorescence microscope under x400 magnification (Olympus AU600 Auto-Biochemical Analyzer; Olympus Corporation, Tokyo, Japan) (19). BrdU-positive cells were counted by eye in 5 random fields of view and the number of BrdU-positive cells is expressed as a percentage of total cells.

Apoptosis assay. Cell apoptosis was determined using the Annexin V, Fluorescein Isothiocyanate (FITC) Apoptosis Detection kit (cat. no. AD10; Dojindo Molecular Technologies, Inc., Kumamoto, Japan). Briefly, following transfection and $48 \mathrm{~h}$ of incubation at $37^{\circ} \mathrm{C}, 1 \times 10^{6}$ cells were collected form each treatment group and suspended in $200 \mu \mathrm{l}$ Annexin V Binding Solution containing $10 \mu \mathrm{l}$ Annexin V-FITC for $15 \mathrm{~min}$ in the dark at room temperature. Subsequently, $300 \mu 1 \mathrm{PBS}$ and $5 \mu \mathrm{l}$ propidium iodide (PI) were added and the samples were immediately analyzed using the FACSCalibur ${ }^{\text {TM }}$ flow cytometer (BD Biosciences) (20). Data were analyzed using BD CellQuest ${ }^{\mathrm{TM}}$ software version 5.1.1 (BD Biosciences).

Western blot analysis. The changes in protein expression in miR-transfected cells were determined by western blot analysis. In brief, $2 \times 10^{5}$ cells were lysed in radioimmunoprecipitation assay lysis buffer (Beyotime Institute of Biotechnology, Haimen, China) on ice for $30 \mathrm{~min}$ and the lysate was centrifuged at $400 \mathrm{x} \mathrm{g}$ for $15 \mathrm{~min}$ at $4^{\circ} \mathrm{C}$. The protein concentration of the supernatant was determined using a bicinchoninic acid protein assay kit (Beyotime Institute of Biotechnology), according to the manufacturer's protocol. Equal amounts $(0.1 \mathrm{mg})$ of protein from each sample were resolved by $10-12 \%$ SDS-PAGE and transferred to polyvinylidene difluoride membranes. Membranes were blocked in 5\% skimmed milk for $1 \mathrm{~h}$ at room temperature and then incubated with the following primary antibodies: p27 (cat. no. ab54563; 1:1,000; Abcam, Cambridge, UK), p21 (cat. no. ab7903; 1:1,000; Abcam), caspase-3 (cat. no. ab13586; 1:1,000; Abcam), AKT (cat. no. 40D4; 1:1,000; Cell Signaling Technology, Inc., Danvers, MA, USA), phosphorylated (p)-AKT (cat. no. 9271; 1:1,000; Cell Signaling Technology, Inc.), BCL2 apoptosis regulator (BCL2; cat. no. ab694; 1:1,000; Abcam), BCL2-associated X apoptosis regulator (Bax; cat. no. ab79217; 1:1,000; Abcam) or actin (cat. no. ab3280; 1:1,000; Abcam) overnight at $4^{\circ} \mathrm{C}$. Subsequently, the blots were incubated with anti-rabbit horseradish peroxidase-conjugated immunoglobulin (Ig) G (cat. no. 7074; 1:1,000; Cell Signaling Technology, Inc.), and anti-mouse horseradish peroxidase-conjugated IgG (cat. no. 7076; 1:1,000; Cell Signaling Technology, Inc.) for $2 \mathrm{~h}$ at room temperature. Finally, bands were visualized by using enhanced chemiluminescence reagent (GE Healthcare Life Sciences, Little Chalfont, UK) (21), and blots were semi-quantifed by densitometry using ImageJ software version 1.49 (National Institutes of Health, Bethesda, MD, USA).

Statistical analysis. All data are presented as the mean \pm standard derivation of three independent experiments. Statistical differences between groups were analyzed by one-way analysis of variance followed by a post hoc Tukey test for 
multiple comparisons. Statistical analysis was performed using GraphPad Prism software version 5 (GraphPad Software, Inc., La Jolla, CA, USA). P $<0.05$ was considered to indicate a statistically significant difference.

\section{Results}

Effects of miR-630 expression on the proliferation of colon cancer cells. After the expression of miR-630 in HCT116 cells was suppressed or overexpressed by transfection with miR-630 inhibitor or mimic, MTT and BrdU assays were performed to investigate the effects of miR-630 dysregulation on the viability and proliferation of colorectal cancer cells. The MTT assay results indicated that cell viability was significantly increased by miR-630 overexpression at days $3(\mathrm{P}<0.01), 4$ $(\mathrm{P}<0.001)$ and $5(\mathrm{P}<0.01)$ of culture, compared with control cells at the same time point (Fig. 1A). However, miR-630 suppression significantly decreased cell viability at the same time points compared with control cells $(\mathrm{P}<0.01$ at day 3; $\mathrm{P}<0.001$ at days 4 and 5; Fig. 1A). The results of the BrdU assay results were consistent with the results from MTT assay; cell proliferation was significantly promoted by miR-630 overexpression $(\mathrm{P}<0.05$; Fig. $1 \mathrm{~B}$ and $\mathrm{C})$ and was significantly inhibited by miR-630 suppression $(\mathrm{P}<0.01$; Fig. $1 \mathrm{~B}$ and $\mathrm{C})$, compared with control cells. Therefore, the results indicate that there may be an association between the expression of miR-630 and cell viability and proliferation.

Effects of miR-630 expression on cell proliferation-associated proteins. In order to investigate the potential mechanism of miR-630 dysregulation on HCT116 cell proliferation, the changes in the protein expression of cell proliferation-associated proteins in miR-transfected cells were analyzed by western blot analysis (Fig. 2). When compared with the control group, the expression of p27 was significantly decreased by miR-630 overexpression $(\mathrm{P}<0.001)$, while p27 expression was significantly increased compared with control cells by miR-630 suppression $(\mathrm{P}<0.001)$. However, the expression of p21 was not significantly changed by miR-630 suppression or overexpression, compared with control cells. Therefore, the effects of miR-630 on cell proliferation may occur by altering the expression of $\mathrm{p} 27$.

Effects of miR-630 expression on colon cancer cells apoptosis. To investigate the effects of miR-630 dysregulation on colorectal cancer cell apoptosis, an annexin V-FITC/PI kit was used to measure the percentage of apoptotic cells following transfection with miR-630 inhibitor, mimic or control. Results in Fig. 3 demonstrated that the percentage of apoptotic cells (quadrants 2 and 4 in flow cytometry plots) was significantly decreased by miR-630 overexpression $(\mathrm{P}<0.01)$ and significantly increased by miR-630 suppression $(\mathrm{P}<0.01)$, compared with the control group. These results indicated that the expression of miR-630 was associated with cell apoptosis, as the percentage of apoptotic cells changed significantly with altered miR-630 expression.

Effects of miR-630 expression on AKT signaling pathway proteins. To assess the potential mechanisms of the effect of miR-630 expression on HCT116 cell apoptosis, changes in the protein expression of AKT signaling pathway proteins in miR-transfected cells were investigated by western blot analysis. As demonstrated in Fig. 4, upregulation of p-AKT $(\mathrm{P}<0.01)$ and BCL2 $(\mathrm{P}<0.001)$, and downregulation of Bax $(\mathrm{P}<0.01)$, procaspase-3 $(\mathrm{P}<0.01)$ and active caspase-3 $(\mathrm{P}<0.05)$ were observed in the miR-630 overexpressed cells compared with the control cells. By contrast, p-AKT and BCL2 expression were significantly downregulated, and Bax, procaspase- 3 and active caspase-3 expression was significantly upregulated in the miR-630-suppressed cells, compared with the control cells. The expression of AKT was not significantly changed by miR-630 suppression or overexpression compared with control cells. Therefore, the effect of miR-630 on cell apoptosis may occur via modulation of the AKT signaling pathway.

\section{Discussion}

There are an increasing number of studies that demonstrate that the dysregulation of miRNAs is widely involved in the pathogenesis of colorectal cancer $(1,9,11,12)$. However, the potential role and underlying mechanisms of miR-630 in colorectal cancer remain to be well demonstrated. In the present study, the expression of miR-630 was suppressed or overexpressed in HCT116 human colorectal cancer cells. The results demonstrated that miR-630 overexpression promoted HCT116 cell proliferation, and the protein expression of proliferation-associated factor $\mathrm{p} 27$ was downregulated by miR-630 overexpression. In addition, in miR-630 overexpressed cells, apoptosis was significantly inhibited, p-AKT and BCL2 protein levels were upregulated, and Bax, procaspase-3 and active caspase- 3 protein levels were downregulated, compared with the control cells. By contrast, miR-630 suppression exerted the opposite effects.

miRNAs can function as either oncogenes or tumor suppressors, depending on the cancer type, by regulating diverse biological processes $(22,23)$. Previous studies have indicated that miR-630 is a tumor suppressor in several types of cancer. Chen et al (14) demonstrated that patients with hepatocellular cancer with low miR-630 expression had higher recurrence rates and shorter overall survival compared with those with high miR-630 expression (14). In addition, Chu et al (24) and Zhao et al (25) demonstrated that miR-630 could induce pancreatic cancer and lung cancer cell apoptosis by modulating its target genes. Conversely, elevated miR-630 expression has also been reported in various types of cancer, including gastric cancer, renal cancer and colorectal cancer (15,24,25). miR-630 may be an independent prognostic marker for patients with these cancer types. Further investigations have identified that miR-630 was associated with poor overall survival in patients with various types of cancer, including gastric, renal and ovarian cancer, and miR-630 could promote the proliferation, invasion and migration of these types of cancer cells (24-27), which indicates that miR-630 may function as an oncogene. The results of the present study also indicate that miR-630 may be an oncogene in colorectal cancer, as overexpression of miR-630 effectively promoted HCT116 cell proliferation and inhibited apoptosis.

To elucidate the potential mechanisms involved in the promotional effect of miR-630 on cell proliferation, the protein expression of two cyclin-dependent kinase inhibitors 
A

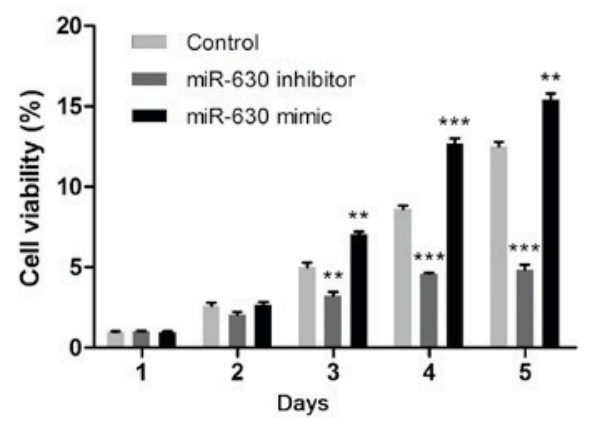

C

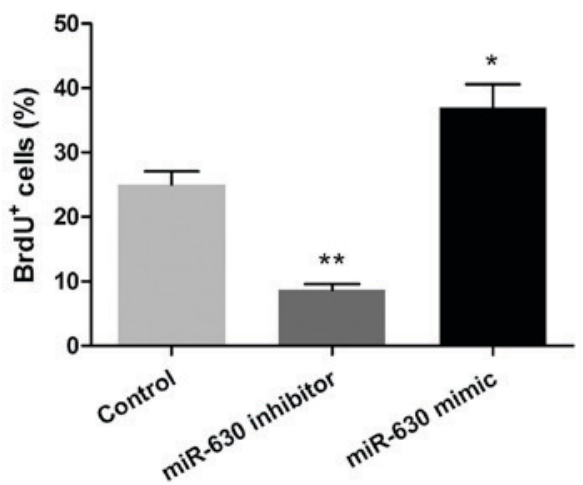

B

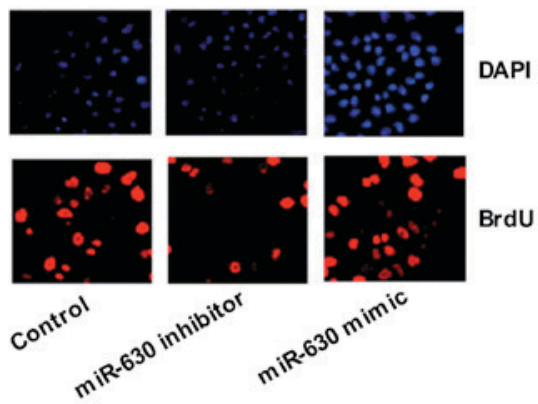

Figure 1. Effects of miR-630 expression on colon cancer cell proliferation. (A) HCT116 cells were first transfected with miR-630 inhibitor, mimic or control, and cell viability was measured by an MTT assay when cells were cultured for 1-5 days. (B) Cell proliferation of miR-transfected cells was detected by a BrdU assay. DAPI was used to stain cell nuclei. Magnification, $\mathrm{x} 400$. (C) Quantification of BrdU staining results. ${ }^{*} \mathrm{P}<0.05,{ }^{* * *} \mathrm{P}<0.01$ and ${ }^{* * * *} \mathrm{P}<0.001 \mathrm{vs}$. control. miR, microRNA; BrdU, bromodeoxyuridine; DAPI, 4', 6-diamidino-2-phenylindole.

A

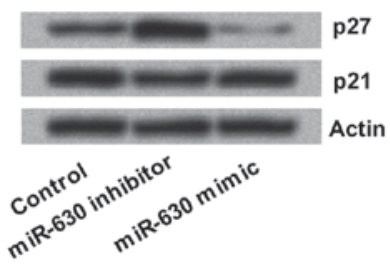

B

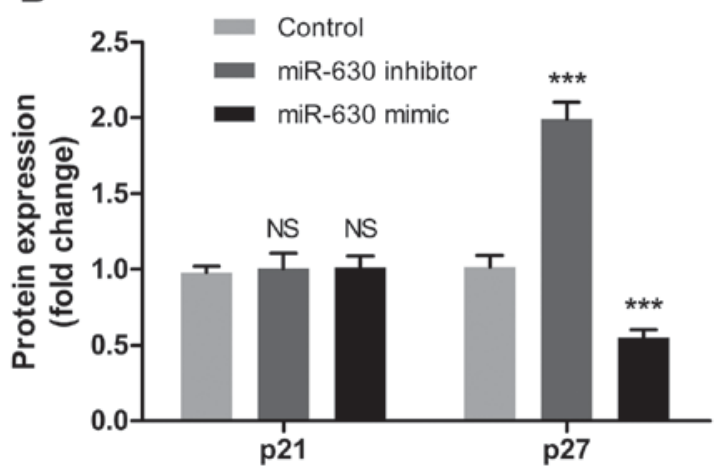

Figure 2. Effects of miR-630 expression on cell proliferation-associated proteins. (A) Western blot analysis of p21 and p27 expression in HCT116 cells transfected with miR-630 inhibitor, mimic or control. (B) Quantification of p21 and p 27 protein expression. Protein expression was normalized to actin. ${ }^{* * *} \mathrm{P}<0.001$ vs. control. miR, microRNA; NS, no significance.

(p21 and p27) were measured. p21 and p27 are essential proteins responsible for arresting cells at G0/G1 phase, and they negatively control cell cycle progression and proliferation (28). Galluzzi et al (29) demonstrated that miR-630 increased levels of p27 in A549 non-small cell lung cancer cells, and subsequently reduced proliferation rates. By contrast, the results of the current study demonstrated that the protein level of p27 in HCT116 cells was downregulated by miR-630 overexpression and the level of p21 was unaffected. This may be because the regulative effects of miR-630 on p27 expression and cell proliferation are complex and depend on the cancer type.
The present study additionally investigated the potential underlying mechanism of miR-630 action on HCT116 cell apoptosis. Phosphatidylinositol-3-kinase (PI3K)/AKT activation has an important role in the majority of cellular processes, including apoptosis (30). AKT is a key mediator in the PI3K/AKT signaling pathway and its phosphorylated form, p-AKT, leads to increases in the expression of the anti-apoptotic protein BCL2, which subsequently reduces the activity of pro-apoptotic protein $\mathrm{Bax}(30,31)$. The imbalance of BCL2/Bax causes cytochrome $c$ release from the mitochondria to the cytosol, which subsequently leads to the activation of the 
A
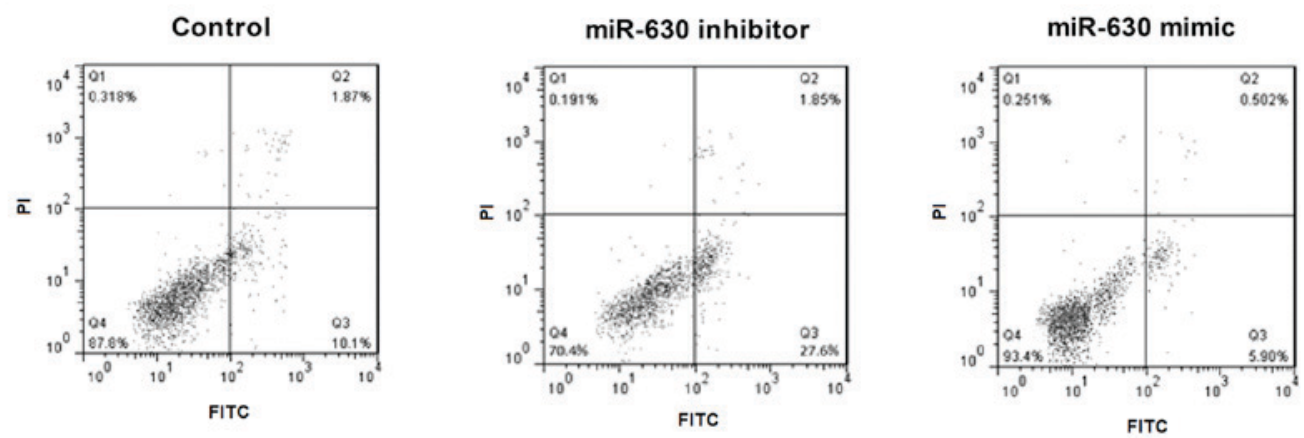

B

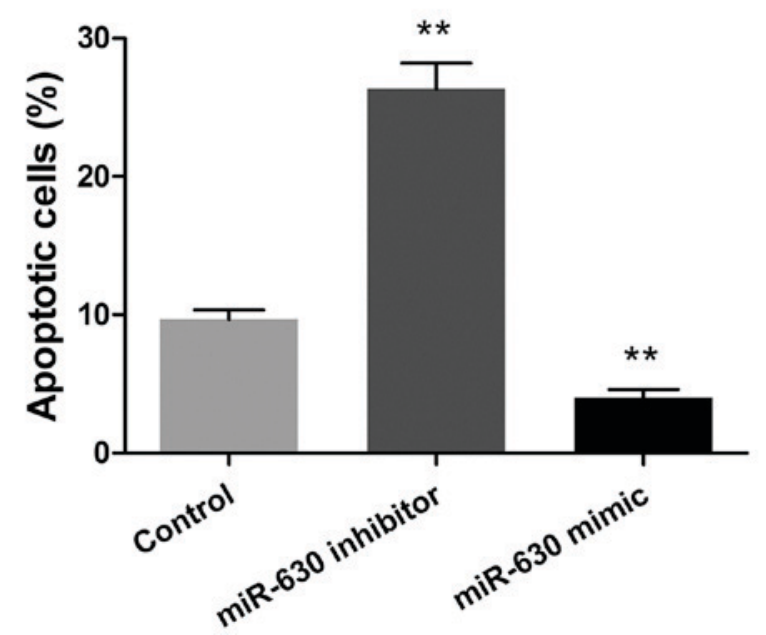

Figure 3. Effects of miR-630 expression on colon cancer cell apoptosis. (A) After HCT116 cells were transfected with miR-630 inhibitor, mimic or control, apoptotic cells were classified by Annexin V-FITC and PI double-staining. (B) Percentage of apoptotic cells (Q2 + Q4) in miR-transfected cells. Q1, dead cells; Q2, late apoptotic cells; Q3, viable cells; Q4, early apoptotic cells. ${ }^{* *} \mathrm{P}<0.01$ vs. control. miR, microRNA; FITC, fluorescein isothiocyanate; PI, propidium iodide; Q, quadrant.

A

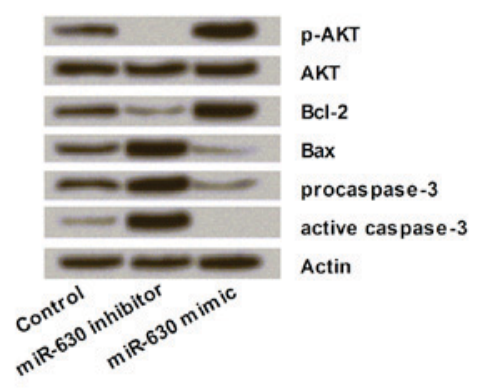

\section{B}

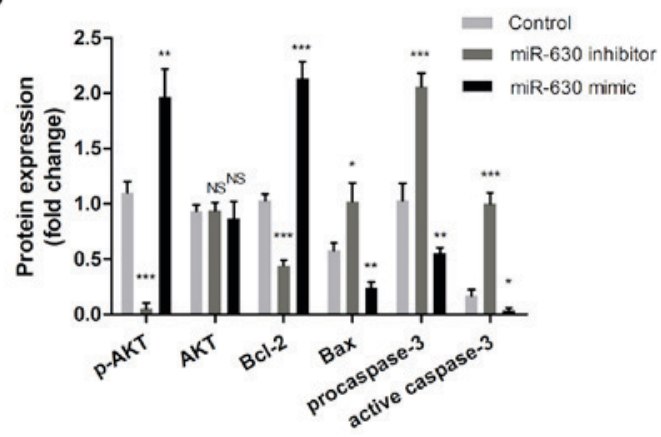

Figure 4. Effects of miR-630 expression on the expression of AKT signaling pathway proteins. (A) Western blot analysis of the protein expression of AKT, p-AKT, BCL2, Bax, procaspase-3 and active caspase-3 in HCT116 cells transfected with miR-630 inhibitor, mimic or control. (B) Quantification of the protein expression. Protein expression was normalized to actin. miR, microRNA; p-, phosphorylated; AKT, protein kinase B; BCL2, BCL2 apoptosis regulator; Bax, BCL2-associated $\mathrm{X}$ apoptosis regulator; NS, no significance. ${ }^{*} \mathrm{P}<0.05,{ }^{* *} \mathrm{P}<0.01$ and ${ }^{* * * *} \mathrm{P}<0.001$ vs. control.

most important executor of cell apoptosis, caspase-3 $(32,33)$. Previous experiments in vitro demonstrated that miR-630 reduced the activation of caspase- 9 and caspase-3, and decreased the expression of Bax triggered by cisplatin (29). In the present study, miR-630 overexpression increased the expression of $\mathrm{p}-\mathrm{AKT}$ and BCL2, and reduced the expression of Bax, procaspase- 3 and active caspase-3. To the best of our knowledge, the current study is the first to report that miR-630 overexpression inhibited cell apoptosis by modulating the AKT signaling pathway in a colorectal cancer cell line. 
In conclusion, the results of the present study demonstrate that miR-630 promoted HCT116 cell proliferation and inhibited apoptosis. These effects may occur via regulation of the expression of p27 and the AKT signaling pathway. Therefore, it is suggested that miR-630 may be a potential oncogene in colorectal cancer, and the inhibition of miR-630 may have potential as an alternative therapeutic strategy for the treatment of patients with colorectal cancer. However, further studies are required to investigate the functions of miR-630 in other types of human colorectal cancer cells, and explore the molecular mechanisms underlying the effects of miR-630 in colorectal cancer cell proliferation and apoptosis.

\section{References}

1. Chen Y, Jiang J, Zhao M, Luo X, Liang Z, Zhen Y, Fu Q, Deng X, Lin X, Li L, et al: microRNA-374a suppresses colon cancer progression by directly reducing CCND1 to inactivate the PI3K/AKT pathway. Oncotarget 7: 41306-41319, 2016.

2. Aan de Stegge WB, van Leeuwen BL, Elferink MA and de Bock GH: The evaluation of more lymph nodes in colon cancer is associated with improved survival in patients of all ages. PLoS One 11: e0155608, 2016.

3. Abdelsatir AA, Husain NE, Hassan AT, Elmadhoun WM, Almobarak AO and Ahmed MH: Potential benefit of metformin as treatment for colon cancer: The evidence so far. Asian Pac J Cancer Prev 16: 8053-8058, 2015.

4. Li C, Xu N, Li YQ, Wang Y and Zhu ZT: Inhibition of SW620 human colon cancer cells by upregulating miRNA-145. World J Gastroenterol 22: 2771-2778,2016.

5. Lewis BP, Burge CB and Bartel DP: Conserved seed pairing, often flanked by adenosines, indicates that thousands of human genes are microRNA targets. Cell 120: 15-20, 2005.

6. Gregory PA, Bert AG, Paterson EL, Barry SC, Tsykin A, Farshid G, Vadas MA, Khew-Goodall Y and Goodall GJ: The miR-200 family and miR-205 regulate epithelial to mesenchymal transition by targeting ZEB1 and SIP1. Nat Cell Biol 10: 593-601, 2008.

7. Lu J, Getz G, Miska EA, Alvarez-Saavedra E, Lamb J, Peck D, Sweet-Cordero A, Ebert BL, Mak RH, Ferrando AA, et al: MicroRNA expression profiles classify human cancers. Nature 435: 834-838, 2005

8. Huang Q, Gumireddy K, Schrier M, le Sage C, Nagel R, Nair S, Egan DA, Li A, Huang G, Klein-Szanto AJ, et al: The microRNAs $\mathrm{miR}-373$ and miR-520c promote tumour invasion and metastasis. Nat Cell Biol 10: 202-210, 2008.

9. Croce CM: Causes and consequences of microRNA dysregulation in cancer. Nat Rev Genet 10: 704-714, 2009.

10. Fan C, Lin Y, Mao Y, Huang Z, Liu AY, Ma H, Yu D, Maitikabili A, Xiao H, Zhang C, et al: MicroRNA-543 suppresses colorectal cancer growth and metastasis by targeting KRAS, MTA1 and HMGA2. Oncotarget 7: 2185-2139, 2016.

11. Teng Y, Mu J, Hu X, Samykutty A, Zhuang X, Deng Z, Zhang L, Cao P, Yan J, Miller D and Zhang HG: Grapefruit-derived nanovectors deliver miR-18a for treatment of liver metastasis of colon cancer by induction of M1 macrophages. Oncotarget 7: 25683-25697, 2016.

12. Taniguchi K, Sakai M, Sugito N, Kumazaki M, Shinohara H, Yamada N, Nakayama T, Ueda H, Nakagawa Y, Ito Y, et al: PTBP1-associated microRNA-1 and -133b suppress the Warburg effect in colorectal tumors. Oncotarget 7: 18940-18952, 2016

13. Zhou CX, Wang CL, Yu AL, Wang QY, Zhan MN, Tang J, Gong XF, Yin QQ, He M, He JR, et al: MiR-630 suppresses breast cancer progression by targeting metadherin. Oncotarget 7: $1288-1299,2016$.

14. Chen WX, Zhang ZG, Ding ZY, Liang HF, Song J, Tan XL, Wu JJ, Li GZ, Zeng Z, Zhang BX and Chen XP: MicroRNA-630 suppresses tumor metastasis through the TGF- $\beta$ - miR-630-Slug signaling pathway and correlates inversely with poor prognosis in hepatocellular carcinoma. Oncotarget 7: 22674-22686, 2016.
15. Chu D, Zheng J, Li J, Li Y, Zhang J, Zhao Q, Wang W and Ji G: MicroRNA-630 is a prognostic marker for patients with colorectal cancer. Tumour Biol 35: 9787-9792, 2014.

16. Jeong KY, Mander P, Sim JJ and Kim HM: Combination of lactate calcium salt with 5-indanesulfonamide and alpha-cyano-4-hydroxycinnamic acid to enhance the antitumor effect on HCT116 cells via intracellular acidification. Oncol Lett 11: 1866-1872, 2016.

17. Wang H, Zhang X, Liu Y, Ni Z, Lin Y, Duan Z, Shi Y, Wang G and Li F: Downregulated miR-31 level associates with poor prognosis of gastric cancer and its restoration suppresses tumor cell malignant phenotypes by inhibiting E2F2. Oncotarget 7: 36577-36589, 2016.

18. Mohseni M, Samadi N, Ghanbari P, Yousefi B, Tabasinezhad M, Sharifi S and Nazemiyeh H: Co-treatment by docetaxel and vinblastine breaks down P-glycoprotein mediated chemo-resistance. Iran J Basic Med Sci 19: 300-309, 2016.

19. Sun CC, Li SJ and Li DJ: Hsa-miR-134 suppresses non-small cell lung cancer (NSCLC) development through down-regulation of CCND1. Oncotarget 7: 35960-35978, 2016.

20. Pan XW and Zhao XH: In Vitro proliferation and anti-apoptosis of the papain-generated casein and soy protein hydrolysates towards osteoblastic cells (hFOB1.19). Int J Mol Sci 16: 13908-13920, 2015.

21. Fantetti KN, Gray EL, Ganesan P, Kulkarni A and O'Donnell LA: Interferon gamma protects neonatal neural stem/progenitor cells during measles virus infection of the brain. J Neuroinflammation 13: 107, 2016.

22. Song YF, Hong JF, Liu DL, Lin QA, Lan XP and Lai GX: miR-630 targets LMO3 to regulate cell growth and metastasis in lung cancer. Am J Transl Res 7: 1271-1279, 2015.

23. Esquela-Kerscher A and Slack FJ: Oncomirs - microRNAs with a role in cancer. Nat Rev Cancer 6: 259-269, 2006.

24. Chu D, Zhao Z, Li Y, Li J, Zheng J, Wang W, Zhao Q and Ji G: Increased microRNA-630 expression in gastric cancer is associated with poor overall survival. PLoS One 9: e90526, 2014.

25. Zhao JJ, Chen PJ, Duan RQ, Li KJ, Wang YZ and Li Y: Up-regulation of miR-630 in clear cell renal cell carcinoma is associated with lower overall survival. Int J Clin Exp Pathol 7: 3318-3323, 2014.

26. Rupaimoole R, Ivan C, Yang D, Gharpure KM, Wu SY, Pecot CV, Previs RA, Nagaraja AS, Armaiz-Pena GN, McGuire M, et al: Hypoxia-upregulated microRNA-630 targets Dicer, leading to increased tumor progression. Oncogene 35: 4312-43620, 2016.

27. Zou YT, Gao JY, Wang HL, Wang Y, Wang H and Li PL: Downregulation of microRNA-630 inhibits cell proliferation and invasion and enhances chemosensitivity in human ovarian carcinoma. Genet Mol Res 14: 8766-8777, 2015.

28. Sun C, Li N, Zhou B, Yang Z, Ding D, Weng D, Meng L, Wang S, Zhou J, Ma D and Chen G: miR-222 is upregulated in epithelial ovarian cancer and promotes cell proliferation by downregulating P27. Oncol Lett 6: 507-512, 2013.

29. Galluzzi L, Morselli E, Vitale I, Kepp O, Senovilla L, Criollo A, Servant N, Paccard C, Hupé P, Robert T, et al: miR-181a and miR-630 regulate cisplatin-induced cancer cell death. Cancer Res 70: 1793-1803, 2010.

30. Briest F and Grabowski P: PI3K-AKT-mTOR-signaling and beyond: The complex network in gastroenteropancreatic neuroendocrine neoplasms. Theranostics 4: 336-365, 2014.

31. Kawiak A and Lojkowska E: Ramentaceone, a naphthoquinone derived from drosera sp., induces apoptosis by suppressing PI3K/Akt signaling in breast cancer cells. PLoS One 11: e0147718, 2016.

32. Wang L, Gai P, Xu R, Zheng Y, Lv S, Li Y and Liu S: Shikonin protects chondrocytes from interleukin-1beta-induced apoptosis by regulating PI3K/Akt signaling pathway. Int J Clin Exp Pathol 8: 298-308, 2015.

33. Antonsson B: Bax and other pro-apoptotic Bcl-2 family 'killer-proteins' and their victim the mitochondrion. Cell Tissue Res 306: 347-361, 2001. 